Original Research Article

\title{
A one year case control study on oxytocin use in labor and its effect on maternal: fetal outcomes
}

\author{
Devendra Singh Kushwah ${ }^{1 *}$, Beenu Kushwah ${ }^{2}$
}

${ }^{1}$ Department of Pharmacology, Gajra Raja Medical College, Gwalior, Madhya Pradesh, India ${ }^{2}$ Department of Gynecology, S.S. Medical College, Rewa, Madhya Pradesh, India

Received: 07 February 2018 Accepted: 12 February 2018

\section{*Correspondence to: \\ Dr. Devendra Singh Kushwah, Email: dev_singh433@ yahoo.com}

Copyright: (C) the author(s), publisher and licensee Medip Academy. This is an openaccess article distributed under the terms of the Creative Commons Attribution NonCommercial License, which permits unrestricted noncommercial use, distribution, and reproduction in any medium, provided the original work is properly cited.

\begin{abstract}
Background: Oxytocin is a drug commonly administered drug to a pregnant lady during labor, nowadays even without an indication, in the hope that the progress of labor can be improved and the need for cesarean delivery may be reduced. This study emphasizes the need for using safeguards like use of checklists before starting oxytocin augmentation, therefore ensuring its rational use to minimize maternal and neonatal complications when augmenting labor with oxytocin, including rigorous indications, use of minimal useful dose and careful efficacy evaluation.

Methods: This is a retrospective, Case-Control, descriptive and analytical study. Study population included women delivering in labor room of Gandhi Memorial Hospital associated with Shyam Shah Medical College, Rewa, from July 2015 to June 2016, then after data were compiled and assessed in department of pharmacology G.R. Medical College, Gwalior.

Results: Results show that the use of oxytocin in labor stimulation can be detrimental to both the mother and the newborn, since they indicate that the use of oxytocin is associated with increased cesarean section rates both in primiparous and multiparous. Furthermore, it was also observed, a significant association between stimulation with oxytocin and low Apgar scores at 1 and 5 minutes both, of the newborns.

Conclusions: Therefore, it may conclude that stimulation with oxytocin should not be used without any indication, but only in very specific cases, in which its use is particularly necessary. These results provide to health professionals a better understanding of the effects of the use of oxytocin during labor, which can be useful for decision-making in clinical practice.
\end{abstract}

Keywords: Apgar score, Labour augmentation, Oxytocin

\section{INTRODUCTION}

Oxytocin was isolated and synthesized for the first time in 1953 by Vincent du Vigneaud who was awarded the Nobel Prize for Chemistry for this discovery two years later. Oxytocin is a commonly used drug in labor and it can be applied in all stages of labor. Oxytocin has been increasingly used over the years, and is currently one of the most common drug employed in obstetrics. ${ }^{1}$ Its use in delivery rooms in the Western world has reached epidemic levels, with percentages of use of between $44.5-75 \%$ in nulliparous and between $25-40 \%$ in multiparous. ${ }^{2-4}$ In a low socio-economic country like India it has often been used as a labor augmentation method to clear out the labor wards as early as possible because of a vast deficiency of doctors as well as infrastructure to accommodate huge number of laboring females, in these kinds of settings its use has been extended universally without even any indication. The association between oxytocin use, hyperstimulation, fetal distress and adverse neonatal outcome are well known. ${ }^{5-9}$ Indeed, adverse perinatal outcome, related to fetal hypoxia due to impairment of gas 
exchange between contractions, may occur in the presence of uterine hyperactivity. ${ }^{9,10}$

It is well known that there is a linear relationship between the amount of oxytocin administered during labor and acid base equilibrium at birth, and that hyperactive uterine contraction pattern and oxytocin use are the most important risk factors for academia at birth. ${ }^{11}$ Moreover, increased uterine contractility is a risk factor for hypoxic/ischemic encephalopathy in full-term newborns. ${ }^{12}$ It is known that, in addition to the classic endocrine functions in female animals during parturition and lactation, oxytocin acts as a potent modulator of social behavior in a diverse range of species from worms and voles to humans. ${ }^{13}$ In particular, recent evidence shows that newborns' neurobehavioral cues may be sensitive to intrapartum oxytocin. ${ }^{14}$

In experiments on animals, the administration of oxytocin during labor was seen to have long term effects with regard to bonding, social, behavior and on the hypothalamicpituitary-adrenal axis, many of these effects show sexually dimorphic behavior. ${ }^{15}$ There are evidences, coming from studies on humans show that the use of oxytocin in labor has effects on the maternal hormone balance. In a study a significant negative correlation was noted in mothers who had received oxytocin infusion during labor: the higher the dose of oxytocin received during labor, the lower their endogenous oxytocin levels two days later. ${ }^{16}$ Authors know that the mothers' plasma oxytocin in post partum is related to the amount of affectionate parenting behaviors, including "motherese" vocalizations, the expression of positive affect, and affectionate touch, whereas paternal plasma oxytocin is correlated with the degree of stimulatory parenting behavior, including proprioceptive contact, tactile stimulation, and object presentation. ${ }^{17}$

It is because of above mentioned reasons that The Institute for Safe Medication Practices designated oxytocin as a high-alert medication. ${ }^{18}$ Yet its use in a busy labor room like ours is rampant, which compelled us to perform this retrospective one year case control study to evaluate the maternal and fetal outcomes of unintended oxytocin infusion as a labor expediting method.

\section{METHODS}

This is a retrospective, Case-Control, descriptive and analytical study carried out in a tertiary hospital associated with a Teaching Institute which primarily serves women from the city and a huge rural area surrounding it. About 9,000 women are assisted a year for childbirth in this hospital. This was a hospital record based retrospective case control study.

\section{Population}

Study population included women delivering in labor room of Gandhi Memorial Hospital associated with Shyam Shah Medical College, Rewa, from July 2015 to June 2016 then after data were compiled and assessed in Department of Pharmacology G.R. Medical College, Gwalior.

\section{Inclusion and exclusion criteria}

All the primi and second gravida women with singleton term pregnancies were included. Presence of any high-risk factor medical or obstetrical disqualified the women.

A hospital record-based study done. All the women fulfilling inclusion criteria were divided in two groups of case and control; case was those who received oxytocin augmentation and control were those who did not receive oxytocin augmentation, data were collected for the characteristics of study population regarding maternal are, gravidity, length of second stage of labor, mode of delivery, presence of PPH, Apgar score of newborn at 1 and 5 minutes, neonatal admissions to intensive care.

\section{Analysis}

The case and control groups were compared with chi square test for the data collected. Statistical significance was defined as a $\mathrm{p}$ value of $<0.05$. Analyses were performed with Stata V.11software (Stata Corporation).

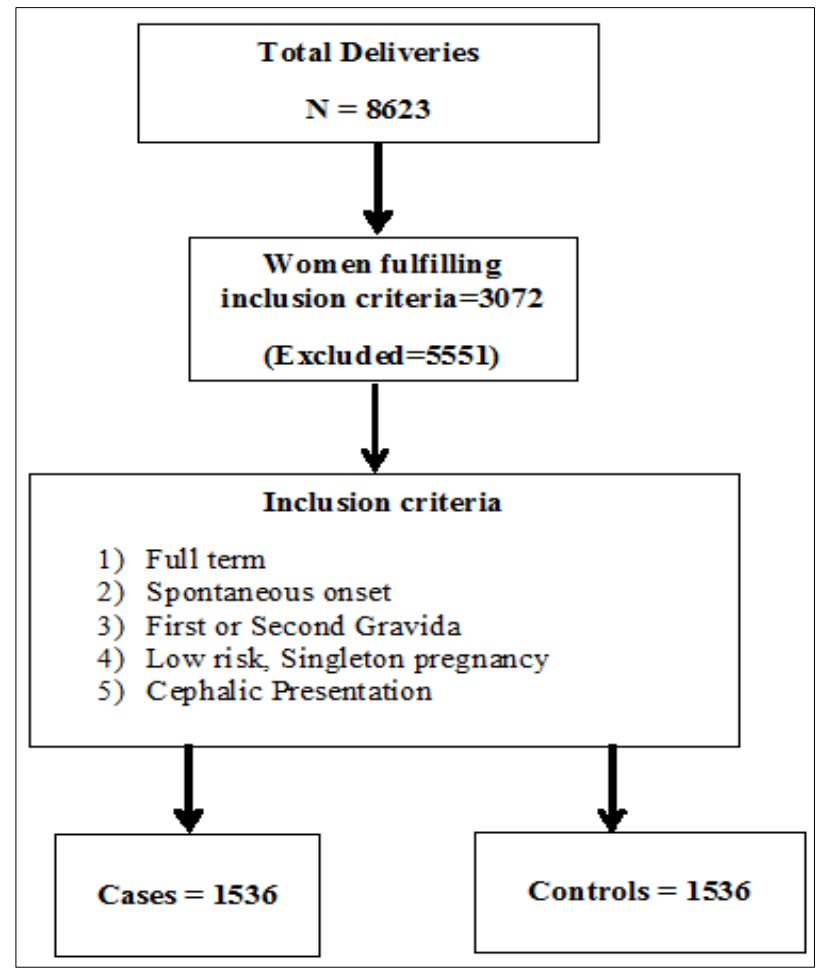

Figure 1: Consort diagram: methodology of study.

\section{Stimulation with oxytocin}

It is defined as the administration of oxytocin to improve and/or increase the frequency and intensity of contractions in women whose delivery begins spontaneously. Oxytocin perfusion consisted of a dilution of five units of oxytocin 
in $500 \mathrm{ml}$ of saline. The perfusion started with the use of $6 \mathrm{ml} / \mathrm{h}$, which was doubled every 30 minutes up to a maximum of $96 \mathrm{ml} / \mathrm{h}$, until achieving adequate contractions. It is used in women with spontaneous labor onset, in situations in which there is low frequency and/or intensity of uterine contractions or when the expansion process has failed and not progressed; although it is also used in other cases to increase uterine activity and thus accelerate the delivery process.

The Ethics Committee of the same hospital where this research was carried out approved the study design.

\section{RESULTS}

During this period total of 4863 deliveries took place. After meeting inclusion criteria of this study, authors could recruit 1536 women in each group. Results have been demonstrated in Table 1. Demographic criteria in each group were comparable. In case group (women receiving oxytocin augmentation) cesarean delivery performed in 401 women while in control group (women not receiving oxytocin augmentation) it was performed in 317 women, $\mathrm{P}$ value was $<0.005$, which is significant. 179 women in case group and 86 women in control group had some grade of Post Partum Hemorrhage, therefore higher in case group and highly significant statistically.

Table 1: Demographic profile.

\begin{tabular}{|lll|}
\hline $\begin{array}{l}\text { Demographic / } \\
\text { clinical factor }\end{array}$ & $\begin{array}{l}\text { Case group } \\
\text { (total 1536) }\end{array}$ & $\begin{array}{l}\text { Control group } \\
\text { (total 1536) }\end{array}$ \\
\hline $\begin{array}{l}\text { Maternal Age in } \\
\text { years }\end{array}$ & $24.8(6.4)$ & $24.5(6.2)$ \\
\hline Parity in number & $1.3(1.1)$ & $1.2(1.3)$ \\
\hline $\begin{array}{l}\text { Gestational age in } \\
\text { weeks }\end{array}$ & $37.1(1.6)$ & $37.6(1.8)$ \\
\hline $\begin{array}{l}\text { Oxytocin onset to } \\
\text { delivery in hours }\end{array}$ & $8.1(4.4)$ & $7.9(4.6)$ \\
\hline $\begin{array}{l}\text { Active phase length } \\
\text { in hours }\end{array}$ & $5.1(1.3)$ & $4.6(1.2)$ \\
\hline $\begin{array}{l}\text { Second stage Length } \\
\text { in hours }\end{array}$ & $0.69(0.58)$ & $0.74(0.91)$ \\
\hline Apgar at 1 minute & $6.6(1.1)$ & $7.2(0.78)$ \\
\hline Apgar at 5 minute & $8.7(1)$ & $8.8(0.98)$ \\
\hline Cesarean delivery & 401 & 317 \\
\hline $\begin{array}{l}\text { Newborn intensive } \\
\text { care unit admission } \\
\text { for more than 48 } \\
\text { hours }\end{array}$ & 79 & 51 \\
\hline $\begin{array}{l}\text { Post Partum } \\
\text { Hemorrhage }\end{array}$ & 179 & 86 \\
\hline
\end{tabular}

*Figures with Standard deviation are shown in mean while others viz. cesarean deliveries, $\mathrm{PPH}$

Cases and Newborn intensive care admissions are in absolute numbers.

In case group mean Neonatal Apgar at 1 minute was 6.6 (SD 1.1) while in control group it was 7.2 (SD 0.78) which is also highly significant statistically. 5 minute Apgar was 8.7 (SD 1) in case group and 8.8 (SD 0.98) in control group, which was significant ( $\mathrm{p}$ value- <0.05). Neonatal admission was done for 79 newborns in case group while in control group for 51 newborns, which was higher in case group but not statistically significant.

Overall results of this study clearly indicate that oxytocin usage in labour is an independent risk factor for poor maternal and fetal outcome.

\section{DISCUSSION}

The observation of no significant difference in reduction in labor duration in the oxytocin group is also similar to earlier reports in which decrease in duration of labor varies from 50 to 162 minutes which may or may not be significant. ${ }^{19-23}$ In our study incidence of PPH was found to be very high in case group which was highly significant and is comparable with other studies. ${ }^{24,25}$ One small casecontrol study of 108 women found that women with PPH were exposed to higher amounts of oxytocin during labor. ${ }^{25}$ In a population-based study including 153000 women, Sheiner et al reported a significant association between labor augmentation with oxytocin and $\mathrm{PPH}$ (adjusted OR: 1.4). ${ }^{26}$ Two other studies found similar ORs, with a risk of hemorrhage 1.6 times higher in women receiving oxytocin during labor. ${ }^{24,27}$

The neonatal outcomes of this study are consistent with those of previous studies, regarding the variable 5-min Apgar score, as found in our study too, other authors found differences, namely a greater percentage of infants born vaginally from mothers stimulated with oxytocin, with Apgar scores per minute $<=7$, compared with mothers non-submitted to stimulation. ${ }^{28}$ In some studies neonatal cord $\mathrm{pH}$ was used as the indicator of fetal compromise and statistically significant differences were observed when $\mathrm{pH}$ values of umbilical cord blood of newborns of mothers stimulated with oxytocin were compared with those of mothers non-submitted to stimulation. Accordingly, oxytocin use was associated with lower $\mathrm{pH}$ values. ${ }^{11,29} \mathrm{In}$ another study of cases and controls, carried out in 2013, the results of women with and without birth planning were compared and better results were observed in the $\mathrm{pH}$ of umbilical cord blood of newborns of mothers with birth planning, which were characterized by presenting a more spontaneous birth process and less use of oxytocin and other interventions. ${ }^{30}$ Some other studies have associated the use of protocols with high doses of oxytocin with higher rates of hospitalization in the neonatal unit, which is reduced when protocols with lower doses of oxytocin are used. ${ }^{31}$

\section{CONCLUSION}

Authors have found an independent association between oxytocin infusion during labor and mode of delivery between both the groups. Our observation of the statistical difference in the caesarean section rate between early 
oxytocin and expectant care groups corresponds well to earlier conclusions in meta-analyses that the use of early oxytocin may or may not decrease the caesarean section rate.

Funding: No funding sources

Conflict of interest: None declared

Ethical approval: The study was approved by the Institutional Ethics Committee

\section{REFERENCES}

1. Holmgren S, Silfver KG, Lind C, Nordström L. Oxytocin augmentation during labor: how to implement medical guidelines into clinical practice. Sex Reprod Healthc. 2011;2(4):149-52.

2. Tracy SK, Sullivan E, Wang YA, Black D, Tracy M. Birth outcomes associated with interventions in labour amongst low risk women: a population-based study. Women Birth. 2007;20(2):41-8.

3. Blix E, Pettersen SH, Eriksen H, Røyset B, Pedersen EH, Øian P. Use of oxytocin augmentation after spontaneous onset of labor. Tidsskr Nor Laegeforen. 2002;122(14):1359-62.

4. Selin L, Almström E, Wallin G, Berg M. Use and abuse of oxytocin for augmentation of labor. Acta Obstet Gynecol Scand. 2009;88(12):1352-7.

5. Herbst A, Wolner-Hanssen P, Ingemarsson I. Risk factors for acidemia at birth. Obstet Gynecol. 1997;90(1):125-30.

6. Liston WA, Campbell AJ. Dangers of oxytocininduced labour to fetuses. $\mathrm{Br}$ Med $\mathrm{J}$. 1974;3(5931):606-7.

7. Klink F, Grosspietzsch R, Klitzing LV, Oberheuser F. Uterine contraction intervals and transcutaneous levels of fetal oxygen pressure. Obstet Gynecol. 1981;57(4):437-40.

8. Vanner T, Gardosi J. Intrapartum assessment of uterine activity. Baillieres Clin Obstet Gynaecol. 1996;10(2):243-57.

9. Johnson N, van Oudgaarden E, Montague I, McNamara $H$. The effect of oxytocin-induced hyperstimulation on fetal oxygen. $\mathrm{Br} \mathrm{J}$ Obstet Gynaecol. 1994;101(9):805-7.

10. Simpson KR, James DC. Effects of oxytocin-induced uterine hyperstimulation during labor on fetal oxygen status and fetal heart rate patterns. Am J Obstet Gynecol. 2008;199(1):34.e1-5.

11. Jonsson M, Nordén-Lindeberg S, Ostlund I, Hanson U. Acidemia at birth, related to obstetric characteristics and to oxytocin use, during the last two hours of labor. Acta Obstet Gynecol Scand. 2008;87(7):745-50.

12. Hayes BC, McGarvey C, Mulvany S, Kennedy J, Geary MP, Matthews TG, King MD. A case-control study of hypoxic-ischemic encephalopathy in newborn infants at $>36$ weeks gestation. Am J Obstet Gynecol. 2013;209(1):29.e1-19.
13. Insel TR. The challenge of translation in social neuroscience: a review of oxytocin, vasopressin, and affiliative behavior. Neuron. 2010;65(6):768-79.

14. Bell AF, White-Traut R, Rankin K. Fetal exposure to synthetic oxytocin and the relationship with prefeeding cues within one hour postbirth. Early Hum Dev. 2013;89(3):137-43.

15. Carter CS. Developmental consequences of oxytocin. Physiol Behav. 2003;79(3):383-97.

16. Handlin L. Human-Human and Human-Animal Interaction. Some Common Physiological and Psychological Effects. Doctoral Thesis, Swedish University of Agricultural Sciences, Skara, 2010.

17. Gordon I, Zagoory-Sharon O, Leckman JF, Feldman R. Oxytocin and the development of parenting in humans. Biol Psychiatry. 2010;68(4):377-82.

18. Institute for Safe Medical Practices. High alert medications. [Accessed February 20, 2014]; Available at: www.ismp.com.

19. Fraser W, Vendittelli F, Krauss I, Breart G. Effects of early augmentation labour with amniotomy and oxytocin in nulliparous women: a metaanalysis. Br J Obstet Gynaecol. 1998;105:189-94.

20. Sadler LC, Davison T, McCowan LM. A randomised controlled trial and meta-analysis of active management of labour. BJOG. 2000;107:909-15.

21. Thornton JG, Lilford RJ. Active management of labour: current knowledge and research issues. BMJ. 1994;309:366-9.

22. Frigoletto FD Jr, Lieberman E, Lang JM, Cohen A, Barss V, Ringer S, et al. A clinical trial of active management of labor. N Engl J Med. 1995;333:74550.

23. Rogers R, Gilson GJ, Miller AC, Izquierdo LE, Curet LB, Qualls CR. Active management of labor: does it make a difference? Am J Obstet Gynecol. 1997; 177:599-605.

24. Combs CA, Murphy EL, Laros RK. Factors associated with postpartum hemorrhage with vaginal birth. Obstet Gynecol. 1991;77:69e76.

25. Grotegut CA, Paglia MJ, Johnson LN, et al. Oxytocin exposure during labor among women with postpartum hemorrhage secondary to uterine atony. Am J Obstet Gynecol. 2011;204:56.e1e6.

26. Sheiner E, Sarid L, Levy A. Obstetric risk factors and outcome of pregnancies complicated with early postpartum hemorrhage: a population-based study. J Matern Fetal Neonatal Med. 2005;18:149-54.

27. Sosa CG, Althabe F, Belizan JM. Use of oxytocin during early stages of labor and its effect on active management of third stage of labor. Am J Obstet Gynecol. 2010;204:238.e1-5.

28. Raba G, Baran P. Obstetric outcomes in oxytocinrelated and spontaneous deliveries-analysis of 2198 cases. Ginekol Pol. 2009;80(7):507-11.

29. Selo-Ojeme D, Rogers C, Mohanty A, Zaidi N, Villar $\mathrm{R}$, Shangaris $\mathrm{P}$. Is induced labour in the nullipara associated with more maternal and perinatal morbidity? Arch Gynecol Obstet. 2011;284(2):33741. 
30. Hidalgo-Lopezosa P, Rodríguez-Borrego MA, Muñoz- Villanueva MC. Are Birth plans associated with improved maternal or neonatal outcomes? MCN Am J Matern Child Nurs. 2013;38(3):150-6.

31. Lewis LS, Pan HY, Heine RP, Brown HL, Brancazio LR, Grotegut CA. Labor and pregnancy outcomes after adoption of a more conservative oxytocin labor protocol. Obstet Gynecol. 2014 May;123(1):66S.

Cite this article as: Kushwah DS, Kushwah B. A one year case control study on oxytocin use in labor and its effect on maternal: fetal outcomes. Int $\mathbf{J}$ Basic Clin Pharmacol 2018;7:391-5. 